Pesq. Vet. Bras. 30(6):479-483, junho 2010

\title{
Carcinoma bronquíolo-alveolar em leão-africano (Panthera leo) $^{1}$
}

\author{
Ricardo B. Lucena ${ }^{2}$, Rafael A. Fighera ${ }^{3}$, Adriano B. Carregaro ${ }^{4}$, Maria Andréia \\ Inkelmann² e Claudio S.L. Barros ${ }^{3 *}$
}

\begin{abstract}
Lucena R.B., Fighera R.A., Carregaro A.B., Inkelmann M.A. \& Barros C.S.L. 2010. [Bronchioloalveolar carcinoma in an African Lion (Panthera leo).] Carcinoma bronquíolo-alveolar em leão-africano (Panthera leo). Pesquisa Veterinária Brasileira 30(6):479483. Departamento de Patologia, Universidade Federal de Santa Maria, Camobi, Santa Maria, RS 97105-900, Brazil. E-mail: claudioslbarros@uol.com.br

A case of diffuse bronchioloalveolar carcinoma of the mixed type was diagnosed in the lung of an adult female African lion (Panthera leo) with presenting signs of progressive dyspnea and weight loss. In all pulmonary lobes there were multiple $0.2-0.5 \mathrm{~cm}$ in diameter soft and homogenous white nodules. Histologically, these nodules consisted of neoplastic cells with an alveolar and papillary disposition, a pattern reminiscent of the preexistent pulmonary structure. The cytoplasms of numerous neoplastic cells were positive in the periodic acid-Schiff (PAS) stain. At immunohistochemistry examination, all neoplastic cells reacted strongly and uniformly to pancytokeratin; focal reactivity for thyroid transcription factor 1 (TTF-1) was observed in the nucleus of neoplastic cells mainly in those at the margins of the nodules. Positive reaction for surfactant $A$ was observed in multifocal areas, both in the cytoplasm and plasma membranes of neoplastic cells. The diagnosis of diffuse bronchioloalveolar carcinoma of the mixed type was made based on histological, histochemistry and immunohistochemistry findings. This seems to be the first report of a primary malignant neoplasm in the lung of the African lion.
\end{abstract}

INDEX TERMS: Felid, Panthera leo, oncology, pathology, pulmonary carcinoma.

RESUMO.-Um caso de carcinoma bronquíolo-alveolar difuso do tipo misto foi diagnosticado em um leão-africano (Panthera leo), hospitalizado com sinais de dispnéia e emagrecimento progressivo. Em todos os lobos pulmonares havia múltiplos nódulos esbranquiçados, macios e homogêneos, de 0,2-0,5cm em diâmetro. Histologicamente, os nódulos eram constituídos por células neoplásicas arranjadas em alvéolos e papilas sustentados por moderado estroma fibrovascular, um padrão que lembrava a estrutura pulmonar pré-existente. Na reação pelo ácido periódico de Schiff

\footnotetext{
${ }^{1}$ Recebido em 16 de novembro de 2009.

Aceito para publicação em 20 de abril de 2010.

2 Programa de Pós-Graduação em Medicina Veterinária, área de concentração em Patologia Veterinária, Centro de Ciências Rurais (CCR), Universidade Federal de Santa Maria (UFSM), Camobi, Santa Maria, RS 97105-900, Brasil.

${ }^{3}$ Departamento de Patologia, Centro de Ciências da Saúde, UFSM, Santa Maria, RS. *Pesquisador $1 \mathrm{~A}$ do CNPq. Autor para correspondência: claudioslbarros@uol.com

${ }^{4}$ Departamento de Clínica de Pequenos Animais, CCR, UFSM, Santa Maria, RS.
}

(PAS) foi observada marcação positiva no citoplasma de numerosas células neoplásicas. Todas as células neoplásicas demonstraram forte e uniforme imunorreatividade citoplasmática para pancitoceratina. A marcação para o fator 1 de transcrição da tireóide (TTF-1) foi observada em focos nos núcleos das células neoplásicas das margens dos nódulos. Nas secções avaliadas para surfactante A, a marcação foi observada em múltiplas áreas focais, tanto no citoplasma como na membrana citoplasmática das células neoplásicas. O diagnóstico de carcinoma bronquíolo-alveolar difuso do tipo misto foi feito com base nos achados histológicos, histoquímicos e imuno-histoquímicos. Essa parece ser a primeira descrição de um neoplasma pulmonar primário maligno em leão-africano.

TERMOS DE INDEXAÇÃO: Doenças de leões, oncologia, patologia, carcinoma pulmonar.

\section{INTRODUÇÃO}

Neoplasmas primários de pulmão são pouco comuns em animais, diferentemente do que ocorre em humanos, em que são descritos mundialmente como os mais frequentes 
e mortais tipos de câncer (Parkin et al. 2004). O carcinoma bronquíolo-alveolar (CBA) é um neoplasma pulmonar caracterizado pela proliferação celular ao longo dos alvéolos pulmonares e junções bronquíolo-alveolares pré-existentes, o que mantém a arquitetura do pulmão. Em medicina veterinária, o CBA é o neoplasma primário de pulmão mais prevalente em cães e gatos, mas é incomum em outras espécies. Tumores bronquíolo-alveolares geralmente ocorrem como nódulos isolados ou na forma de múltiplas massas na periferia do pulmão; raramente tais tumores podem ocorrer de forma difusa (Wilson \& Dungworth 2002). Histologicamente, neoplasmas primários de pulmão podem ser confundidos com metástases pulmonares de outras formas de câncer. Nesses casos, a avaliação imunohistoquímica é imprescindível para confirmar a verdadeira origem pulmonar (Ramos-Vara et al. 2005).

Neoplasmas são pouco descritos em leões (Panthera leo); quando relatados se restringem ao tegumento e aos sistemas alimentar, hematopoético, reprodutor, nervoso e esquelético (Dorso et al. 2008, Owston et al. 2008, Tucker et al. 2008, Taylor et al. 1976). No conhecimento dos autores, até o momento, não há descrição na literatura de neoplasma primário maligno afetando o Sistema Respiratório em leão-africano. Foi descrito apenas um adenoma pulmonar como um achado incidental em um leão submetido à eutanásia em decorrência de um oligodendroglioma encefálico (Tucker et al. 2008). Este relato tem como objetivo descrever os aspectos clínicos, patológicos e imunohistoquímicos do carcinoma bronquíolo-alveolar em um leão.

\section{MATERIAL E MÉTODOS}

Um espécime de leão-africano (Panthera leo), fêmea, adulto, com histórico de dispneia e emagrecimento progressivos foi atendido no Hospital Veterinário Universitário da Universidade Federal de Santa Maria (HVU-UFSM) e necropsiado no Laboratório de Patologia Veterinária da UFSM (LPV-UFSM). Fragmentos de diversos órgãos foram fixados em formol a 10\%, embebidos em parafina, seccionados a $3 \mu \mathrm{m}$, corados com hematoxilina e eosina (HE) e submetidos a técnicas histoquímicas que incluíram o ácido periódico de Schiff (PAS) e o tricrômico de Masson (TM). Avaliação imuno-histoquímica foi realizada pela técnica da estreptavidina-biotina-peroxidase (LSAB Kit Peroxidase Universal, DakoCytomation ${ }^{5}$ ) em diferentes secções do pulmão. A imunomarcação foi visualizada com o uso de 3-3'diaminabenzidina (DAB). As secções foram contracoradas com hematoxilina de Harris; utilizaram-se controles positivos e negativos para cada anticorpo. Inicialmente utilizou-se anticorpo anti-pancitoceratina (policlonal, DakoCytomation ${ }^{5}$ ), na diluição de 1:2000, e anti-vimentina (clone V9, DakoCytomation ${ }^{5}$ ), na diluição de 1:100. As secções foram testadas também com antiproteína S-100 (policlonal, DakoCytomation ${ }^{5}$ ), na diluição de 1:5000, e anti-cromogranina A (clone DAK-A3, DakoCytomation ${ }^{5}$ ), na diluição de 1:600. Para confirmar a origem pulmonar das células neoplásicas, as secções foram avaliadas para a presença do TTF-1 (clone 8G7G3/1, DakoCytomation ${ }^{5}$ ), na diluição de 1:50, e da apoproteína surfactante A (clone PE10, DakoCytomation ${ }^{5}$ ), na diluição de 1:800.

\footnotetext{
${ }^{5}$ Dako Cytomation, 6392 Via Real, Carpinteria, CA, USA.
}

\section{RESULTADOS}

Na necropsia foi confirmado o péssimo estado corporal. Em todos os lobos pulmonares havia múltiplos nódulos de 0,2$0,5 \mathrm{~cm}$ de diâmetro. Ao corte, os nódulos eram macios e apresentavam-se homogeneamente esbranquiçados. Histologicamente, os nódulos eram constituídos por células neoplásicas arranjadas em alvéolos e papilas com moderado estroma fibrovascular, um padrão que lembrava a estrutura pulmonar pré-existente (Fig.1). As células neoplásicas eram cuboides ou colunares baixas, mas variavam de tamanho e forma em algumas áreas (pleomorfismo moderado). Essas células tinham citoplasma eosinofílico e abundante; o núcleo era grande, redondo, disposto basalmente e formado por cromatina agregada com nucléolo único e inconspícuo. Ocasionais células com núcleo excêntrico, citoplasma abundante e com um único e grande vacúolo ("células em anel de sinete") foram observadas. Em múltiplas áreas dos nódulos havia corpos de psammoma no interstício (Fig.2). Mitoses eram pouco frequentes. Em extensas áreas do pulmão havia espessamento dos septos alveolares por macrófagos e tecido conjuntivo (Fig.3). Grande quantidade de fluido proteináceo, associado com fibrina e neutrófilos íntegros, era visto no interior dos alvéolos.

Na reação com o PAS foi observada marcação positiva no citoplasma de numerosas células neoplásicas, o que permitiu interpretar essas células como secretoras de mucina. Nas "células em anel de sinete" o vacúolo observado na HE reagia fortemente com o PAS (Fig.4). Nas reações com tricrômico de Masson houve marcação de extensas áreas de colágeno, demonstrando a marcada fibrose (desmoplasia).

Todas as células neoplásicas demonstraram forte e uniforme imunorreatividade citoplasmática para pancitoceratina (Fig.5). Na avaliação para vimentina, a expressão foi negativa nas células neoplásicas e positiva no tecido conjuntivo associado ao neoplasma. As secções testadas com anti-

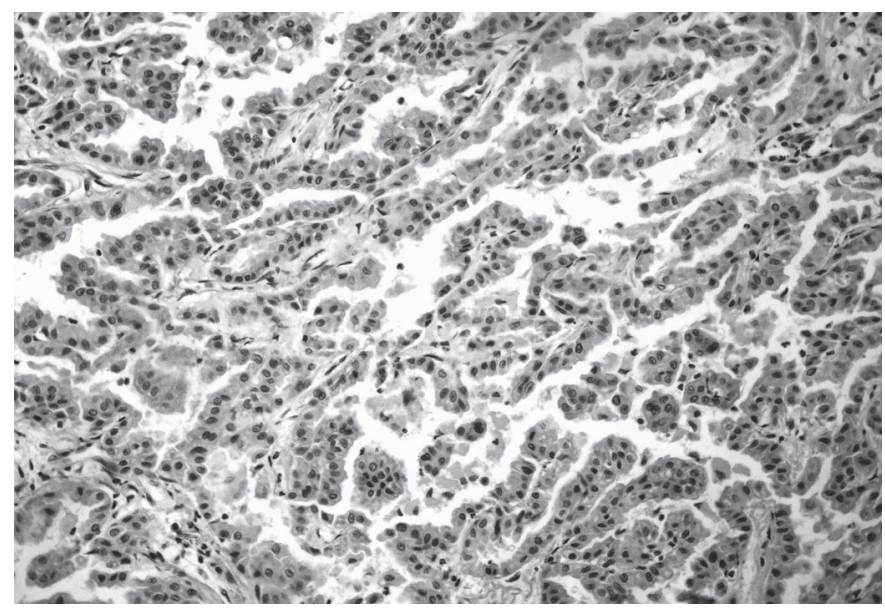

Fig.1. Pulmão, carcinoma bronquíolo-alveolar. As células neoplásicas estão arranjadas em alvéolos, que, por vezes, projetam-se como papilas, e são sustentadas por escasso estroma fibrovascular. Observe que o padrão pulmonar préexistente foi preservado. HE, obj.10x. 
Fig.2. Pulmão, carcinoma bronquíolo-alveolar. Material anfofílico e radiado no interstício pulmonar (corpos de psammoma). Observe que a direita há três outros corpos menores coalescendo no interior de um alvéolo. HE, obj.40x.

Fig.4. Pulmão, carcinoma bronquíolo-alveolar. Células ricas em mucina fortemente marcadas pela reação com o ácido periódico de Schiff. PAS, obj.40x.

Fig.6. Pulmão, carcinoma bronquíolo-alveolar. Foco de marcação positiva para o fator 1 de transcrição da tireóide em uma junção bronquíolo-alveolar neoplásica. A marcação é apenas nuclear. Imuno-histoquímica, método da estreptavidina-biotina-peroxidase, contra-coloração com hematoxilina de Harris, obj.40x.

Fig.3. Pulmão, carcinoma bronquíolo-alveolar. No interstício, há deposição de tecido conjuntivo fibroso e acentuado infiltrado inflamatório constituído principalmente por macrófagos. HE, obj.40x.

Fig.5. Pulmão, carcinoma bronquíolo-alveolar. Marcação forte e uniforme para pancitoceratina no citoplasma das células neoplásicas. Imuno-histoquímica, método da estreptavidina-biotina-peroxidase, contra-coloração com hematoxilina de Harris, obj.20x.

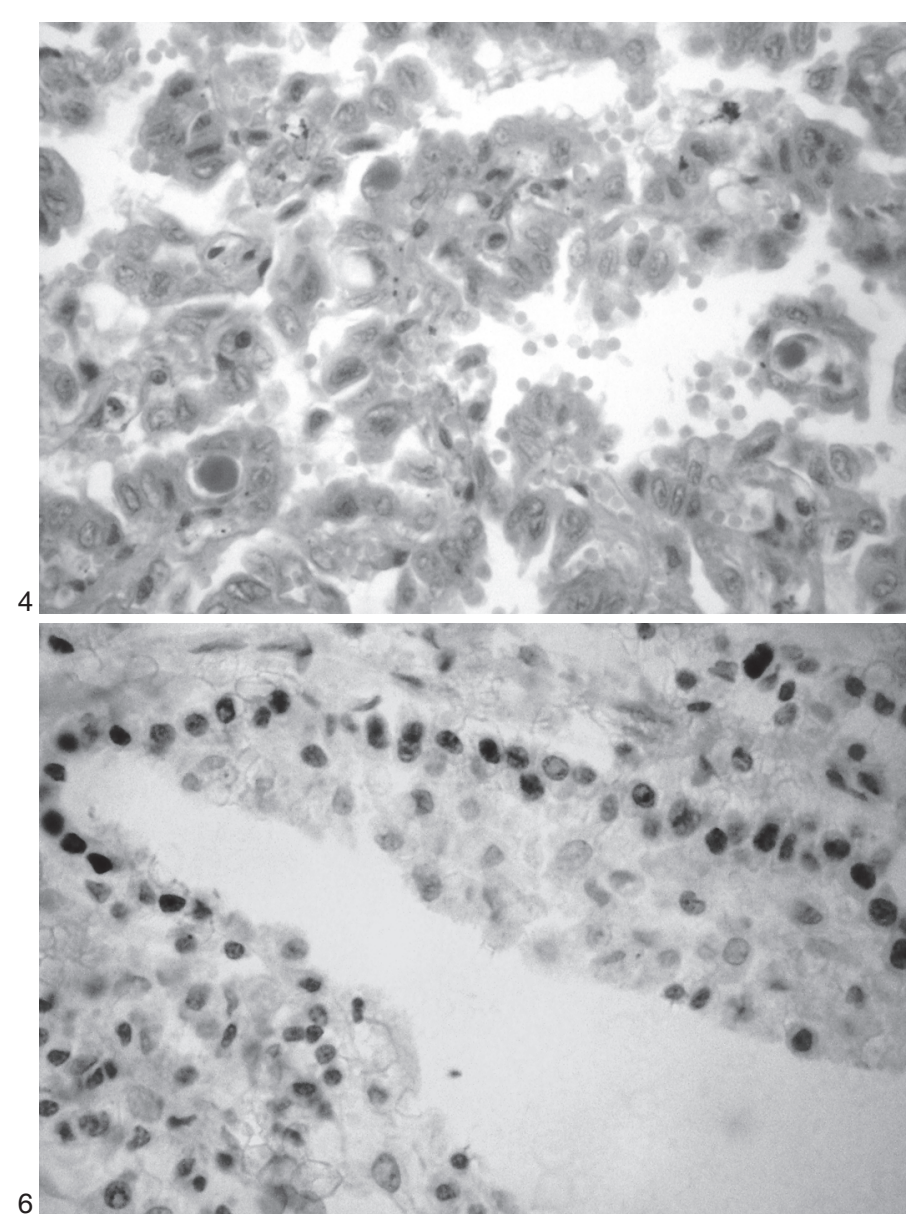

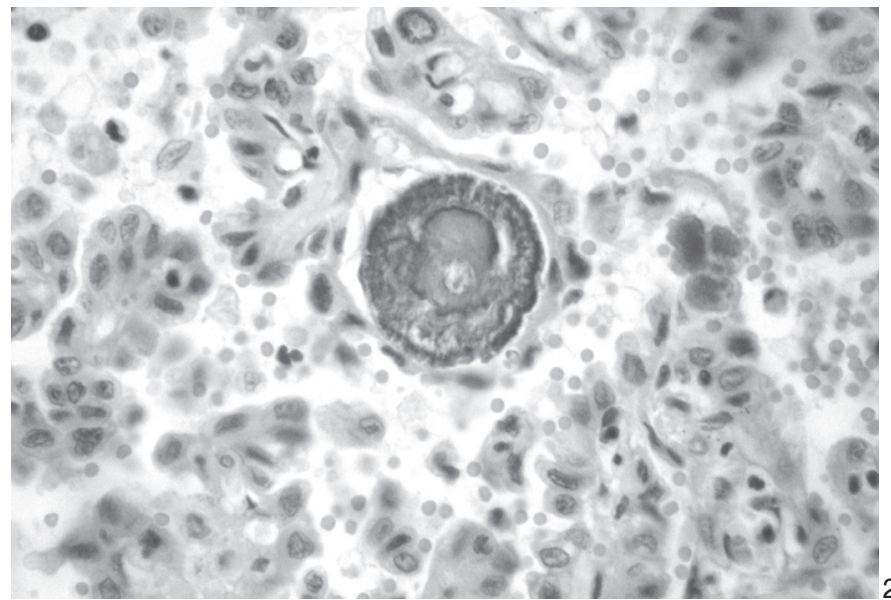
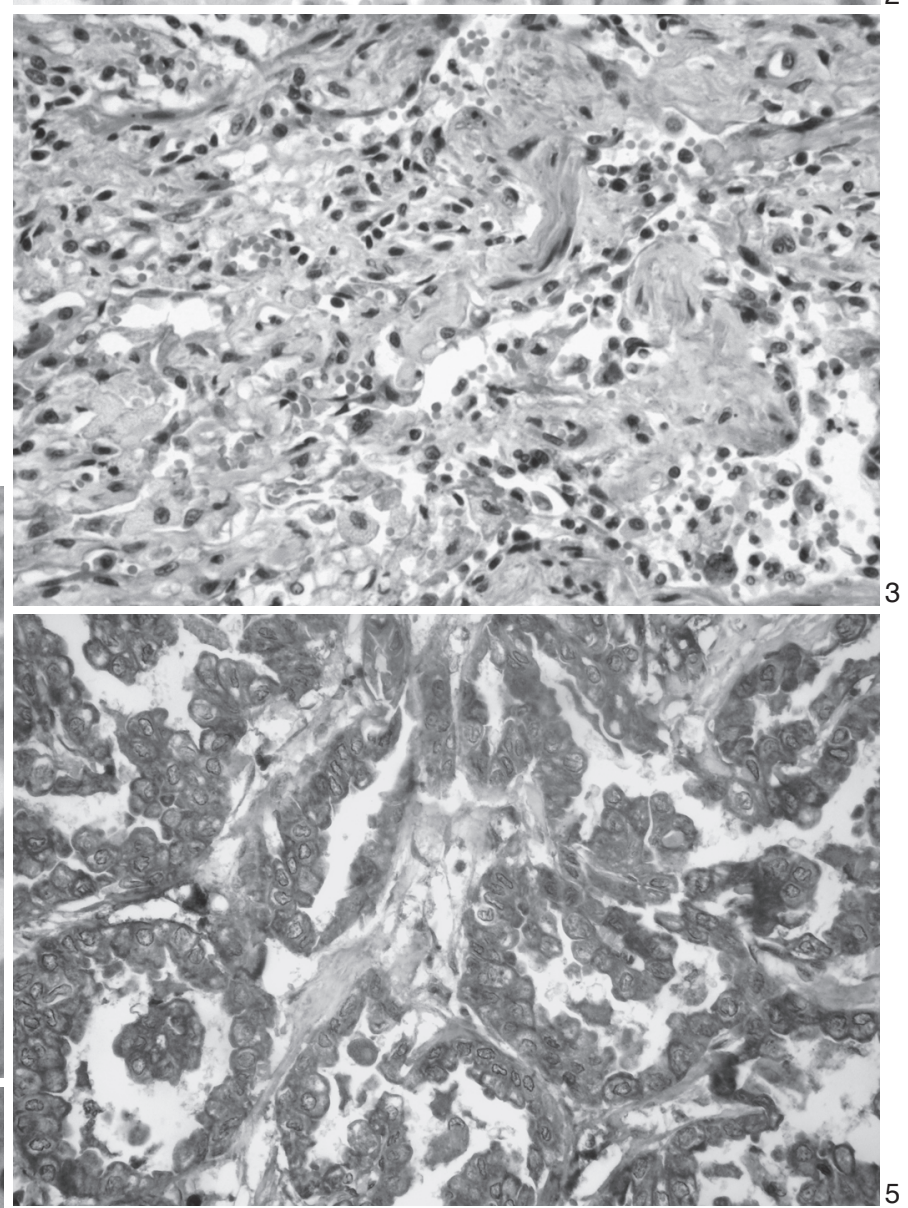

proteína S-100 e anti-cromogranina A foram negativas. A marcação para o TTF-1 foi observada em focos, principalmente nas células neoplásicas das margens dos nódulos, marcando apenas o núcleo (Fig.6). Nas áreas onde o neoplasma era composto por células secretoras de mucina não houve marcação para o TTF-1. Nas secções avaliadas para surfactante $A$, a marcação foi observada em múltiplas áreas focais, tanto no citoplasma como na membrana citoplasmática das células neoplásicas (Fig.7). Com base nesses achados o diagnóstico definitivo foi de carcinoma bronquíolo-alveolar difuso do tipo misto. 


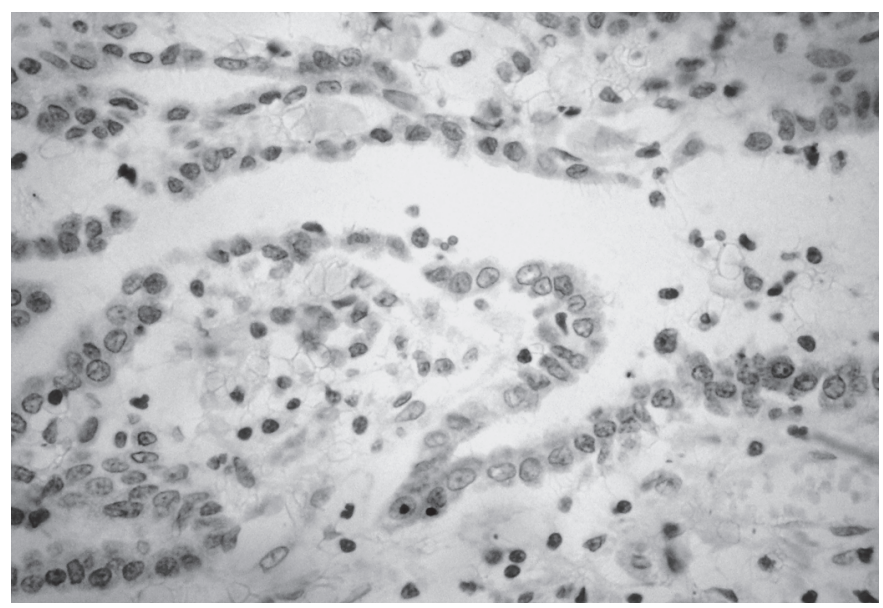

Fig.7. Pulmão, carcinoma bronquíolo-alveolar. Foco de marcação positiva para apoproteína surfactante A em um alvéolo neoplásico. A marcação é apenas citoplasmática. Imuno-histoquímica, método da estreptavidina-biotina-peroxidase, contra-coloração com hematoxilina de Harris, obj.40x.

\section{DISCUSSÃO}

As lesões neoplásicas observadas no pulmão eram graves o suficiente para explicar a acentuada dispneia apresentada por esta leoa e foram responsáveis pelo atendimento clínico ao qual o animal foi submetido. As extensas áreas de fibrose associadas ao tumor, possivelmente induzidas pelas células neoplásicas, levaram a um diagnóstico tentativo inicial de fibrose pulmonar idiopática felina espontânea, descrita em gatos (Williams et al. 2004), mas esse diagnóstico foi posteriormente afastado em razão da fibrose ser, neste caso, pouco significativa ${ }^{6}$.

A classificação dos tumores de pulmão em humanos e animais é baseada no sítio de origem, no padrão histológico ou na combinação desses (Wilson \& Dungworth, 2002). Neste caso, a avaliação histológica foi compatível com carcinoma bronquíolo-alveolar (CBA), uma vez que revelou células neoplásicas com citoplasma abundante, que foram PAS-positivas, e células com moderada quantidade de citoplasma, que foram PAS-negativas, caracterizando um CBA do tipo misto. O CBA é um neoplasma originado dos pneumócitos tipo Il ou das células de Clara e o padrão misto tem sido descrito em outras espécies animais (Wilson \& Dungworth, 2002).

O pulmão é um dos principais sítios de metástases de neoplasmas não pulmonares, o que faz com que muitas vezes seja difícil distinguir neoplasmas pulmonares primários de metástases (Ramos-Vara et al. 2005). Estudos imuno-histoquímicos em neoplasmas primários de pulmão são imprescindíveis para posterior estabelecimento de pro-

\footnotetext{
${ }^{6}$ Lâminas dessa lesão foram examinadas pelo Dr. Kurt Williams, patologista norte-americano do Diagnostic Investigation, College of Veterinary Medicine, Michigan State University, que descreveu a fibrose pulmonar idiopática felina espontânea em gatos. O Dr. Williams afastou a possibilidade se tratar dessa condição pela falta de fibrose significativa.
}

tocolos seguros de diagnóstico. Neste caso, a avaliação inicial demonstrou imunomarcação positiva para pancitoceratina e negativa para vimentina nas células neoplásicas, confirmando a origem epitelial do neoplasma em questão. Para comprovar a origem primária pulmonar, foram realizadas análises para TTF-1 e apoproteína surfactante A. O TTF-1 é uma proteína originalmente identificada nas células foliculares da tireoide, mas também foi observada nas células respiratórias e em áreas do cérebro em desenvolvimento (Lau et al. 2002). O TTF-1 tem sido apontado como um marcador altamente específico em adenocarcinomas pulmonares de humanos e de cães (Lau et al. 2002, Ramos-Vara et al. 2005). Na leoa deste relato, a marcação para TTF-1 foi observada em focos na periferia dos nódulos pulmonares. Nos locais de acentuada necrose e inflamação a marcação foi fraca ou ausente. Nas áreas compostas por células secretoras de mucina não foi observado marcação. Em humanos também não há expressão para esse anticorpo em CBA do tipo mucinoso (Lau et al. 2002). Neste caso, a marcação para TTF-1 foi superior a marcação para apoproteína surfactante A, essa observação foi constatada também em humanos, no qual apenas $57 \%$ dos CBA foram positivos para apoproteína surfactante A contra $71 \%$ de positividade nos casos testados para TTF1 (Kaufmann \& Dietel 2000). A marcação negativa nas secções testadas com cromogranina A serviu para excluir a possibilidade de tratar-se de tumor neuroendócrino ou de metástases de neoplasmas endócrinos.

\section{CONCLUSÕES}

No nosso conhecimento, esta é a primeira descrição de neoplasma pulmonar primário maligno em leão-africano.

O neoplasma comprometeu acentuadamente o parênquima pulmonar e foi responsável por um quadro respiratório grave.

De acordo com a distribuição e padrão histológico, o neoplasma foi classificado como carcinoma bronquíoloalveolar difuso do tipo misto.

A origem pulmonar foi confirmada através da técnica de imuno-histoquímica (positiva para pancitoceratina, TTF1 e apoproteína surfactante A) e o padrão histológico foi estabelecido através da HE e da histoquímica (padrão misto de reação ao PAS).

Agradecimentos.- Aos patologistas do Diagnostic Center for Population and Animal Health, Michigan State University, Lansing, MI, EUA, Ingeborg M. Langohr, Rebecca Smedleye e Kurt Williams, pela disponibilidade em dar sua opinião acerca dos aspectos histopatológi$\cos$ do caso aqui relatado.

\section{REFERÊNCIAS}

Dorso L., Risi E., Triau S., Labrut S., Nguyen F., Guigand L., Wyers M. \& Abadie J. 2008. High-grade mucoepidermoid carcinoma of the mandibular salivary gland in a lion (Panthera leo). Vet. Pathol. 45:104-108.

Kaufmann O. \& Dietel M. 2000. Thyroid transcription factor- 1 is the superior immunohistochemical marker for pulmonary adenocarcinomas and large cell carcinomas compared to surfactant proteins A and B. Histopathology 36:8-16. 
Lau S.K., Luthringer D.J. \& Eisen R.N. 2002. Thyroid transcription factor1: A review. Appl. Immunohistochem Mol. Morphol. 10:92-102.

Owston M.A., Ramsay E.C. \& Rotstein D.S. 2008. Neoplasia in felids at the Knoxville Zoological Gardens, 1979-2003. J. Zoo Wildl. Med. 39:608-613.

Parkin M., Tyczynski J.E., Boffetta P., Samet J., Shields P. \& Caporaso N. 2004. Lung cancer epidemiology and etiology, p.12-15. In: Travis W.D., Brambilla E., Müller-Hermelink H.K. \& Harri C.C. (Eds), Tumours of the lung, pleura, thymus and heart. World Health Organization classification of tumours. IARC Press, Lyon.

Ramos-Vara J.A., Miller M.A. \& Johnson G.C. 2005. Usefulness of thyroid transcription factor-1 immunohistochemical staining in the differential diagnosis of primary pulmonary tumors of dogs. Vet. Pathol. 42:315-320.

Taylor R.F., Park R.D. \& Kollias G. 1976. Osteochondroma in a lioness. J. Am. Vet. Med. Assoc. 169:966-967.

Tucker A.R., Ramsay E.C. \& Donnell R.L. 2008. Oligodendroglioma in an African lion (Panthera leo). J. Zoo Wildl. Med. 39:650-654.

Williams K., Malarkey D., Cohn L., Patrick D., Dye J. \& Toews G. 2004. Identification of Spontaneous Feline Idiopathic Pulmonary Fibrosis. Chest 125:2278-2288

Wilson D.W. \& Dungworth D.L. 2002. Tumors of the respiratory tract, p.365-399. In: Meuten D.J. (Ed.), Tumors in Domestic Animals. $4^{\text {th }}$ ed. lowa State University Press, Ames. 